be at least a part of the picture because a marginally significant proportion of straight lines seem to be directed towards key solar positions at the horizon that could have signalled the season when water ran in the canals; this time generally coincides quite closely with the overhead passage of the Sun.

For pictures of the lines, as opposed to people who have studied them, Morrison's book is the preferable of the two with its beautifully illustrated Chapter 6 entitled "The Nazca Lines - A Pictorial Survey". Hadingham has the better bibliography, which will carry lay readers about as far as they should care to go. But in the final analysis both of these books are about more than Nazca and its mysteries, and ought to cause us to reflect on some deeper questions about ourselves and how we view the past. They also show how much Nazca has become the refuge of the iconoclast. There have been too many short-term programmes and not enough long-term cooperative research, yet the absence of facts fails to deter codecrackers from offering answers. Experts on measuring units, astronomy and computers will not solve this problem. As both authors imply, to understand Nazca we must know about people - and they are far more complicated than higher mathematics.

Anthony F. Aveni is Charles A. Dana Professor of Astronomy and Anthropology at Colgate University, Hamilton, New York 13346, USA. $H e$ is the editor of The Lines of Nazca, to be published next year by the American Philosophical Society.

\section{Before the invasion}

\section{Nick Saunders}

The Great Journey: The Peopling of Ancient America. By Brian M. Fagan. Thames \& Hudson, London/W.W. Norton, New York: 1987. Pp. 288. £14.95, \$19.95.

Explaining the presence of America's indigenous population has exercised the minds of scholar and layman alike ever since Columbus accidentally discovered the New World in 1492, promptly but erroneously labelling its inhabitants as Indians. Europeans, their intellectual curiosity sparked by the appearance of 50 Brazilian Indians at the court of King Henri II of France in 1550, offered such explanations as Atlantic crossings by Carthaginians or Phoenicians, and the wanderings of the ten tribes of Israel. In 1589, the Jesuit José de Acosta suggested with some prescience that American Indians had first come from Asia by land and perhaps a short sea voyage. Today, although the arguments are less speculative and more informed, they are no less heated.

American archaeology is divided into two camps by the evidence for early man in the New World. There are those, such as Alan Bryan and Richard MacNeish, who believe that, despite the sparse and often ambiguous data, America was colonized well before $c$. 10,000 years BP, during the Wisconsin glaciation. In support of this view they cite dates between 30,000 and 19,000 BP from sites such as Tlapacoya in Mexico, Pikimachay in Peru and Boqueirāo de Pedra Furada in Brazil. The majority opinion, however, regards human occupation as beginning with the Clovis culture, securely dated to $c$. 11,000 BP; that culture was replaced a thousand years later by the equally well documented Folsom people. Each is characterized by the distinctively fluted projectile points

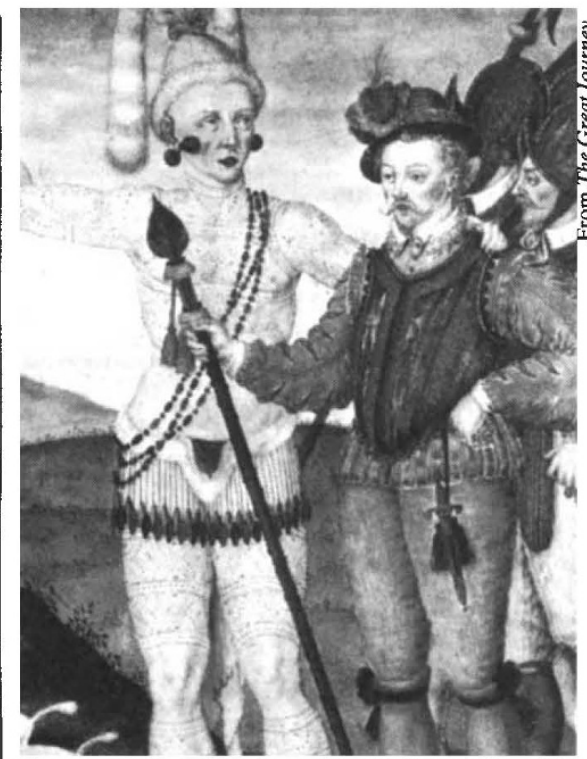

New arrival - Explorer René de Laudonnière with Chief Athore in Florida, 1564. Painted by Jacques Le Moyne.

which the peoples fashioned. In his book Brian Fagan fleshes out the picture of the two cultures by graphically reconstructing their hunting and butchering techniques of both mammoth and bison.

The heart of the disagreement between the two schools of thought often lies with the question of whether stone and bone materials were purposely made artefacts or naturally weathered objects. Highlighting the interpretive disagreements is a site with no stone tools at all. Old Crow in the Canadian Yukon has a confused geology of redeposited sands and gravels, and has yielded mammoth bones characterized by distinctive spiral fractures which the excavators interpreted as man made. Together with an obviously manufactured bone flesher, these remains were dated to c. 27,000 BP. Sceptics, who considered the fractures to be the result of freeze-thaw action and subsurface soil movements, and the flesher as a recent but redeposited implement, have had their suspicions vindicated in recent years by a re-dating of the flesher to $c .1,300 \mathrm{BP}$.

Similar suspicions surround the site of Calico in southern California, currently dated to between 50,000 and 200,000 years ago. Such early dates suggest a preNeanderthal colonization for which there is no corroborative evidence elsewhere in the Americas. The argument for an early Ice Age colonization is difficult to prove archaeologically, but evidence is mounting that slowly pushes back the commonly accepted frontier date of 11,000 BP. Sites such as Meadowcroft in the United States, Bluefish Caves in north-west Canada and Monte Verde in Chile indicate human occupation by at least $12,000 \mathrm{BP}$.

Proponents of an early arrival take great heart from the geological evidence for a land-bridge, called Beringia, which at various times in prehistory linked the Asian and American landmasses. Soundings, deep-sea cores and palynological evidence suggest a series of alternating sea levels between Alaska and Siberia between 25,000 and $14,000 \mathrm{BP}$, during the so-called "Duvanny Yar Interval". At this time the sea level stood between 90 and $100 \mathrm{~m}$ lower than at present, exposing a wide land-corridor across which early man could have migrated. Fagan judiciously reviews the varying opinions about what type of climate existed on this land-bridge - some argue for a harsh tundra environment inimical to animal life; others believe it to have been a unique ecosystem capable, in places, of supporting both animals and human beings.

Although the disputes on dating are unlikely to be easily resolved, there is more agreement over the distinctive physical characteristics of America's indigenous inhabitants. In 1907 Ales Hrdlicka first proposed, on the basis of physical anthropology, that America was probably populated by immigrants from Asia. In recent years Christy Turner, a specialist in human teeth, has isolated a distinctive set of characteristics such as shovelling of the incisors and number of tooth-roots, which he calls "Sinodonty", and which only occur amongst the indigenous populations of northern Asia and the Americas.

As a non-specialist, Fagan has played safe and has opted for the majority view of a later rather than an earlier occupation of the American continent - though sensibly his final judgement is reserved. The Great Journey is an eminently readable account of its subject, in which Fagan carefully pieces together the jigsaw of ambiguous evidence, complex arguments, personalities and discoveries. This is a valuable and long overdue contribution to the popular literature on American archaeology - in addition, it is a fascinating story convincingly told.

Nick Saunders is Course Tutor in New World Archaeology in the Department of Adult Education, University of Southampton, Southampton SO9 $5 \mathrm{NH}, U K$. 